\title{
Coding Error or Statistical Embellishment? The Political Economy of Reporting Climate Aid
}

\author{
Michaelowa, Axel ; Michaelowa, Katharina
}

\begin{abstract}
To benefit from a wide-spread public support for climate policy, aid agencies strive to show the climate relevance of their development activities. Using project-level aid data and country-level political data for 21 DAC donors from 1995 to 2007, we test whether this may lead to politically motivated misreporting. Through keyword search in individual project descriptions and complementary hand-coding we assess all aid activities for their actual climate change-related content, and thereby construct our most relevant control variables. Econometric results reveal that indeed, project coding is influenced systematically by the donor governments' ideological orientation as well as by national voters' environmental preferences.
\end{abstract}

DOI: https://doi.org/10.1016/j.worlddev.2011.07.020

Posted at the Zurich Open Repository and Archive, University of Zurich

ZORA URL: https://doi.org/10.5167/uzh-57323

Journal Article

Published Version

Originally published at:

Michaelowa, Axel; Michaelowa, Katharina (2011). Coding Error or Statistical Embellishment? The Political Economy of Reporting Climate Aid. World Development, 39(11):2010-2020.

DOI: https://doi.org/10.1016/j.worlddev.2011.07.020 


\title{
Coding Error or Statistical Embellishment? The Political Economy of Reporting Climate Aid
}

\author{
AXEL MICHAELOWA and KATHARINA MICHAELOWA* \\ University of Zurich, Switzerland
}

\begin{abstract}
Summary. - To benefit from a wide-spread public support for climate policy, aid agencies strive to show the climate relevance of their development activities. Using project-level aid data and country-level political data for 21 DAC donors from 1995 to 2007 , we test whether this may lead to politically motivated misreporting. Through keyword search in individual project descriptions and complementary hand-coding we assess all aid activities for their actual climate change-related content, and thereby construct our most relevant control variables. Econometric results reveal that indeed, project coding is influenced systematically by the donor governments' ideological orientation as well as by national voters' environmental preferences.

(c) 2011 Elsevier Ltd. All rights reserved.
\end{abstract}

Key words - development assistance, climate policy, public choice, project coding, mitigation, adaptation

"Never trust any statistics that you didn't forge yourself."

(Unknown source, albeit sometimes attributed to Winston Churchill; for details see Frankford (2002))

\section{INTRODUCTION}

In order to assess the contribution of development aid to the objectives of the 1992 UN Conference on Environment and Development in Rio de Janeiro, in 1998, the OECD Development Assistance Committee (DAC) introduced the so called "Rio markers" for reporting aid projects related to biodiversity, desertification and climate change. In this paper, we only consider the marker related to climate change. Some individual donors have used such markers since 1995.

The climate change-related objectives of the Rio Summit, codified in the UN Framework Convention on Climate Change (UNFCCC), refer to the reduction or sequestration of greenhouse gas emissions ("mitigation"). The corresponding Rio marker should therefore indicate aid activities related to the objective of climate change mitigation (OECD-DAC, 2009a, p. 1). However, even at first glance, the list of aid activities reported as climate change-relevant to the DAC reveals a number of curiosities. In the list, we find, for instance:

- Savannah elephant vocalization (US).

- Uniforms for park guardians in Central America (Spain).

- Tobacco control (New Zealand).

- Lead reduction in transport fuels in Pakistan (UK). ${ }^{1}$

- Earthquake safety (Switzerland).

- Monetary climate in Democratic Republic of Congo (Belgium).

- Love movie festival (Belgium).

Most of these obvious coding errors may be related to misunderstandings (e.g., associations of any kind of environmental objectives with climate change) and some may be related to rapid coding procedures. But some might also be related to politico-economic factors, that is, to systematic over-coding for political reasons. In any case, even at first glance, there appear to be too many errors to be purely random.
A closer look at the data confirms this initial impression. There is, indeed, a considerable mismatch between the aid activities coded as climate change-relevant by donors, and those for which keyword search reveals an actual climate change orientation. For a random sample of 115,000 aid projects, Roberts, Starr, Jones, and Abdel-Fattah (2008) find evidence for climate relevant content only for about $25 \%$ of the projects coded as such with the Rio marker. Our own analysis based on all 636,962 aid activities listed in the project level aid (AidData) database for 21 bilateral DAC donors for the years 1995-2008 yields very similar results (see Section 2, Table 1b).

Can such strong discrepancies be purely coincidental, that is, a random error by coding administrators when typing the data into the system? In this paper, we test this hypothesis against the alternative that at least some of the miscoding is systematically related to variables such as the national voters' environmental preferences, meteorological extreme events, or the media coverage of international climate policy issues. Drawing from the wider field of public choice literature, we assume that governments want to maximize political support. Depending on the valuation of environmental policies by the general public, this support may be positively influenced by statistics showing a significant climate change-related effort of development cooperation projects. At the same time, especially when transparency and the level of information are not very high, these projects may not necessarily have anything to do with climate change. The corresponding coding mismatch may be reduced, however, if the government does not only value public support, but also intrinsically values environmental objectives.

To the best of our knowledge, there is no literature on politically motivated project coding so far. There is, however, a substantial amount of literature on politically motivated aid allocation. Ever since the late 1970s, researchers have examined politico-economic determinants of aid allocation (for early studies, see McKinley, 1978; McKinley \& Little, 1979; Maizels \& Nissanke, 1984). ${ }^{2}$ More recently, other aspects of

\footnotetext{
*We thank Christopher Kilby, Martin Stadelmann, Michael Findley, Axel Dreher and three referees for many helpful comments and suggestions. Final revision accepted: May 6, 2011.
} 
Table 1. Donor coding versus authors' recoding

\begin{tabular}{|c|c|c|c|c|}
\hline \multirow[t]{2}{*}{ DAC coding ${ }^{\mathrm{a}}$} & \multicolumn{4}{|c|}{ Authors' recoding } \\
\hline & No climate relevance & Unclear $^{\mathrm{b}}$ & Climate relevance ${ }^{\mathrm{c}}$ & Total \\
\hline \multicolumn{5}{|l|}{ (a) Overview } \\
\hline No climate marker & 614,310 & 0 & 12,238 & 626,548 \\
\hline Climate marker & 3,226 & 2,867 & 4,321 & 10,414 \\
\hline \multirow[t]{2}{*}{ Total } & 617,536 & 2,867 & 16,559 & 636,962 \\
\hline & No mitigation & & Mitigation related & Total \\
\hline \multicolumn{5}{|c|}{ (b) DAC Rio markers versus authors' mitigation coding } \\
\hline No climate marker & 623,294 & & 3,254 & 626,548 \\
\hline Climate marker & 7,616 & & 2,798 & 10,414 \\
\hline \multirow[t]{2}{*}{ Total } & 630,910 & & 6,052 & 636,962 \\
\hline & No adaptation & & Adaptation related & Total \\
\hline \multicolumn{5}{|c|}{ (c) DAC Rio markers versus authors' adaptation coding } \\
\hline No climate marker & 617,545 & & 9,003 & 626,548 \\
\hline Climate marker & 9,137 & & 1,277 & 10,414 \\
\hline Total & 626,682 & & 10,280 & 636,962 \\
\hline \multicolumn{5}{|c|}{$\begin{array}{l}\text { "DAC coding" refers to bilateral donors' reporting to the DAC using the climate-related Rio marker. } \\
\text { "Unclear" refers to cases in which project descriptions were insufficient to assess climate relevance, that is, when the project description contained no } \\
\text { elements to determine either relevance or irrelevance for climate change. "Unclear" coding only appears in the context of positive DAC coding since in } \\
\text { cases in which project descriptions are missing or extremely uninformative, potential climate relevance is only revealed though the DAC coding itself. Such } \\
\text { projects would have been assumed to be climate irrelevant had they not received a Rio marker. Since unclear cases do not even allow us to reassess the } \\
\text { climate coding altogether, the more specific links to mitigation or adaptation cannot be established either. In this Table b and c, these cases are subsumed } \\
\text { in the categories "no mitigation" and "no adaptation". } \\
\text { "If a project is coded "climate relevant" this usually implies that it will also be found in the categories "mitigation related" and/or "adaptation related". } \\
\text { However, there are some cases in which the climate relevance was clear while the concrete project activities were not indicated. Therefore the sum of } \\
\text { projects we code "climate relevant" exceeds the sum of projects we were able to count as relevant for mitigation and adaptation. }\end{array}$} \\
\hline
\end{tabular}

aid, such as the relationship between multilateral donors' policies and the interests of member governments (see e.g., Dreher, Sturm, \& Vreeland, 2009a; Dreher, Sturm, \& Vreeland, 2009b; Kilby, 2009, or the use of specific procedures and instruments of aid delivery, have also been assessed from a politico-economic perspective. For an overview of various aspects of the recent literature on the political economy of aid, see Lahiri and Michaelowa (2006). From a similar perspective, other authors examine discrepancies between donor rhetoric and actual policies (see e.g., Weaver, 2008 for an excellent study on the World Bank) or incentive structures that result in imprecise or biased reporting of project outcomes (Martens, 2002; Michaelowa \& Bormann, 2006). This literature comes closest to our study which intends to contribute to the political economy of aid reporting, that is, to the assessment of political factors that may lead to a misalignment between actual aid allocation and aid allocation reported to the DAC.

The literature on the political economy of climate policy is less comprehensive by far. The recent paper by Bättig and Bernauer (2009) is closely related to our study in that the authors also look at a "words-deeds" gaps in international climate policy. Their results suggest that democratic countries experience larger gaps than nondemocratic ones. Our focus, however, is on aid to developing countries, and on donors, who are all democratic countries anyway. Only very few other studies are explicitly related to developing countries. Flues, Michaelowa, and Michaelowa (2010) discuss the influence of institutional variables on decision making on the Executive Board of the Clean Development Mechanism. And finally, in the context of environmental aid flows, Hicks, Parks, Roberts, and Tierney (2008) use PLAID data to assess donors' incentives to increase aid flows benefiting the environment, while reducing aid that has negative impacts on the environment.
In our study, we specifically consider aid officially dedicated to projects related to climate policy ("climate aid") ${ }^{3}$. The recent availability of "project" level aid data ${ }^{4}$ with individual project descriptions provides us with the unique opportunity to compare actual project content with the donors' own coding of climate relevance. Our hand coding of project level aid data provides the variables which are then fed into a regression to test which parameters could influence donor governments' coding decisions. In Section 2, we first present some descriptive statistics about the problem of coding mismatch. In this context, we also highlight some inconsistencies within the definition of the Rio marker itself that may be responsible for part of the problem. Moreover, we discuss our own keywordbased recoding strategy.

In Section 3 we develop the conceptual framework of our politico-economic analysis based on a political support function model augmented by elements of government ideological orientation. The econometric estimation strategy and the operationalization of the relevant variables are discussed in Section 4. Section 5 provides the empirical results, and Section 6 presents the conclusions of our analysis.

\section{CODING MISMATCH IN CLIMATE AID}

According to the OECD-DAC's definition of Rio markers, agreed to in 1998 ,

"climate-change related aid is defined as activities that contribute to the objective of stabilization of greenhouse gas $(G H G)$ concentrations in the atmosphere at a level that would prevent dangerous anthropogenic interference with the climate system by promoting efforts to reduce or limit $G H G$ emissions or to enhance GHG sequestration." (OECD-DAC, 2002a, p. 4). 
This definition can also be found in virtually all other climate-aid related DAC documents as well as on the OECDDAC homepage (see e.g., OECD-DAC, 1998, 2002b, p. 4, 2009a, p. 1, 2009b). As already mentioned above, it focuses exclusively on climate change mitigation. The objective to adjust to climate change impacts (adaptation) is explicitly excluded from the definition due to the fact that mitigation, rather than adaptation, is the ultimate objective of the UNFCCC (see e.g., OECD-DAC, 2009a, p. 1). To cover adaptation, a different marker was introduced in January 2010 (OECD-DAC, 2010), but has not been used for project coding yet.

At first sight, the DAC definition appears to be very clear and well explained but the distinction between mitigation and adaptation is less clear than it might appear. Directly under the clearly mitigation oriented definition, OECD-DAC (2009b, p. 1) speaks about adaptation when it comes to the clarification of individual scores for the Rio marker. ${ }^{5}$ While this appears to be a simple typo, it may lend itself to some confusion. Moreover, the DAC eligibility criteria for the Rio marker include impact and vulnerability assessments (see OECD-DAC, 2002b, p. 4), which are solely related to adaptation. Another reason for confusion could be the two categories used - the second having climate change mitigation as important issue but not principal objective of the project.

Confusion about the correct definitions may lead to problems of unintended miscoding through lack of clarity, but may also give rise to politically motivated over-coding through the inclusion of adaptation related projects. Development specialists are usually not experts in climate policy, and the actual use of the climate related Rio marker reveals that many projects were recorded as climate relevant due to their link to adaptation, rather than mitigation (see Table 1a-c). This confusion may also arise through the fact that mitigation aims at a global public good that does not provide any specific advantage for the developing country in which the activity takes place, and is therefore not a typical aid activity. This is different for adaptation which gives a clear local benefit to the recipient country.

Table 1a shows that not even half of the 10,414 projects coded as climate relevant by the donors (i.e., a total of 4,321 projects) clearly contribute to either mitigation or adaptation of climate change. For another 2,867 projects, descriptions are so limited that their contribution is not clear. And for about one third of the projects $(3,226$ projects in total), the bilateral donors' coding is clearly inappropriate, that is, projects were coded as climate change-relevant while they are not (not even when including adaptation along with mitigation). At the same time, we observe a high number of cases $(12,238)$ where we find a contribution to climate change mitigation but where bilateral donors did not use the Rio marker.

Of course, the large majority of projects show no climate relevance - from neither the authors', nor the donors' coding. This lies in the nature of development assistance where climate-related objectives are certainly not the top-priority and have only recently become more prominent. These clearly nonclimate relevant projects are not of much interest for our current analysis of over-coding.

Looking more closely at Table $1 \mathrm{~b}$, we see that if the Rio marker were taken seriously as a code only for mitigation related projects, evidence of over-coding would be even stronger. In fact, the numbers reveal that only about one fourth of all projects with Rio marker are actually relevant for mitigation $(2,798$ out of 10,414$)$. The remaining three quarters would be over-coded. If we add projects relevant for adaptation $(1,277$, see Table 1c), the share of over-coded projects is reduced to below $60 \%$. Obviously, this share is still extremely high. Thus, even if we assume that all adaptation related overcoding is solely due to lack of knowledge or insufficiently clear coding directives, we still have a very high share of over-coding to explain by other factors.

Let us now look at those projects which were not reported as climate relevant to the DAC, but still are related to either mitigation or adaptation. Table $1 \mathrm{~b}$ reveals that more than half of the actually mitigation relevant projects since 1995 have not been coded as such. This might, for example, be due to the fact that "normal" hydropower projects are not seen as climate change mitigation despite providing renewable, carbon-free electricity. Similarly, many rural development projects have a mitigation component such as agroforestry. For adaptation the share of relevant but unrecorded projects is still much higher, at almost $90 \%$ (Table 1c). This probably reflects that after all, to some extent, project administrators have realized that the focus of the Rio-coding is mitigation rather than adaptation.

The quality of climate related reporting varies substantially among donor countries. Over-coding is particularly prevalent in the United States, Netherlands and Norway, followed by Portugal, Germany, Denmark, and Austria. In all of these countries, over-coding concerns between $5 \%$ and $46 \%$ of the projects labeled either climate relevant or nonrelevant by the donors themselves. This is substantial considering that the majority of these projects is clearly climate-irrelevant given the nature of aid (for details on all donors, see Appendix B).

Obviously, whatever discrepancies and inconsistencies we find in the data may be, in principle, related as much to mistakes in our own recoding, as to mistakes in the original coding reported by DAC donors. Such errors may arise, in particular, because we had to assess a huge number of projects within very limited time. Since, for the sake of our politicoeconomic analysis, we require information on all projects, we were not able to use an in-depth study of a sub-sample of projects such as Roberts et al. (2008). We were also unable to follow the method of machine based recoding suggested by Roberts, Weissberger, and Peratsakes (2010). They use a specific algorithm allowing a computer to code of the full dataset on the basis of the experience gathered in the initially drawn random sample. Unfortunately, their recoded data have not been available in time for our analysis.

However, given our familiarity with climate related aid projects, and the safeguards we set up through a double-check of all mismatches, we believe that our own coding efforts can be considered as sufficiently reliable in the context of this study. We had the opportunity to cross-check our keywords with those used by Roberts et al. (2008), in order to ensure the inclusion of all important categories. In addition, our own coding tries to avoid the ambiguity of some coding categories (such as "cleaner production" and "air pollution enforcement"). ${ }^{6}$

Many specific examples of miscoding are provided along with a detailed description of our coding procedure in Appendix A of this paper. Appendix A also includes a discussion of certain problems faced during the coding process. Our recoded variables are available in a separate data Appendix D.

\section{A CONCEPTUAL FRAMEWORK FOR POLITICALLY MOTIVATED CODING DECISIONS}

Let us now return to the question whether the strong discrepancies between climate coding by bilateral donors and our recoding based on individual project descriptions can be 
purely coincidental. To some extent, they certainly reflect a lack of expertise with respect to climate policy or unclear information about the new marker. They may also reflect a lack of diligence driven by time and resource constraints, or even a lack of knowledge about the project itself-if some head office administrative staff rather than the project manager assigns these codes (Roberts et al., 2010, p. 3). These reasons for coding mismatch would simply lead to a random error of donor coding.

The mismatch is, however, so substantial that this may be only part of the story. Climate policy has become such a prominent part of international and national policy debates that it could be relevant for electoral decisions. Aid agencies seem to be well aware of the public relevance of climate policy. Anecdotal evidence suggests that high-level staff in aid agencies consider moving toward climate related topics in order to escape from a general aid fatigue (see also Michaelowa \& Michaelowa, 2011). Hicks et al. (2008, p. 160) speak of a "political market for environmental aid in wealthy countries" and argue that "this market is shaped by the preferences of voters within each country." Despite a dominance of discourses about issues such as unemployment, taxes, migration, or trade openness in national election campaigns, evidence shows that at least those political and administrative officials directly responsible for development cooperation care tremendously about their public image, notably before the elections.

How else to explain why, in the mid-1990s, the French DAC delegation went up to the level of the OECD Secretary General to push through a couple of changes in the wording of the DAC Peer Review on the performance of French development aid. Or the German DAC delegation responding to a 50-page draft of the DAC Peer Review by a 70-page fax with requests for "factual changes" briefly before the 1998 general elections? A number of academic studies also suggest the relevance of voters' aid and/or environmental preferences for government policy (see e.g., List \& Sturm, 2006; Milner \& Tingley, 2010).

At times, rhetorical changes (or changes in coding), rather than changes in substance may be sufficient to ensure public support. This should be particularly true for policy areas as difficult to verify as climate aid.

More formally, let us assume a government's utility depends on public support, on the one hand, and on some ideological preferences on the other hand. In line with most of the literature on the political economy of environmental policy making, we do not distinguish between the administrative side and the political side of government (see e.g., Blanke, 2002; Felder \& Schleiniger, 2002; Hicks et al., 2008; List \& Sturm, 2006). To simplify the exposition, we rather imagine an aid administration headed by the relevant minister for development cooperation (reflecting the political side of the aid administration) as a single agent.

Public support is increased through greater evidence for the government's climate change-related activities, especially if environmental objectives are considered important by the country's population (see e.g., Hicks et al., 2008). In our context, this implies that aid statistics showing strong evidence of climate change-related activities will increase public support by an environmentally concerned population in the donor country.

We now consider that this evidence can be generated by either actually increasing climate related activities, or by forging the statistics through over-coding. The former has the disadvantage that subject to a given budget constraint, any additional climate project will lead to the reduction of activities elsewhere. Over-coding, however, can provide the impres- sion of enhanced climate activities without the need to reduce other activities. It will therefore increase government utility.

Unfortunately, this does not lead us to a clear prediction with respect to the impact of the public's valuation of environmental issues. While the literature clearly suggests that the public's ecological preferences are positively correlated with actual environmental policy making (List \& Sturm, 2006; Knill, Debus, \& Heichel, 2010), this is less obvious for overcoding. For instance, voters with environmental preferences may not only value climate related aid, but may also be more critical observers of the government's environmental policies, so that over-coding becomes a risky business. While the sign of the relationship can thus not be unambiguously determined on theoretical grounds, our hunch is that the incentive for over-coding will dominate, because actual detection of wrongly reported aid statistics has been an extremely difficult task so far (given the low level of publicly available information on the details of individual aid activities and the high transaction cost involved in such an analysis). This leads us to our first hypothesis:

H1. Over-coding will be the stronger the more the national population in the donor country values environmental objectives.

Nevertheless, we consider that change in transparency may play a role with respect to the public's critical scrutiny (typically led by NGOs). While there has not been much change over time concerning the transparency of aid activities, information on climate change-related issues has varied over time along with different levels of media coverage. A high level of information may render the obfuscation of over-coding more difficult and thereby increase the risk of discovery. This leads us to our second hypothesis:

H2. Over-coding will be the stronger, the less the national population in the donor country is informed about climate policy issues.

Finally, we assume that the government also has ideological preferences, whereby "ideological" refers to an intrinsic valuation of certain objectives, unrelated to voter preferences and exogenously determined, that is, not explained within our model. This is a typical assumption in models of environmental policy making (see Knill et al., 2010). The consideration of ideology alters the government's optimization problem and complements the purely opportunistic perspective of a simple political support function model. If a government has ecological preferences, an increase of actual climate change-related activities will lead to higher utility even if other activities equally valued by the public will have to be reduced. This implies that at a given level of transparency and public support of environmental issues, a government with ecological preferences will generate more truly climate relevant activities. As long as reporting incentives remain unchanged, this should reduce the gap between actual and reported climate related aid activities, and thereby lead to less over-coding. This leads us to our final hypothesis:

H3. The prevalence of over-coding is reduced if the government has ecological preferences.

However, is it not conceivable that reporting incentives increase, too? It certainly would if we relaxed our simplifying assumption of considering the administrative and the political 
part of the government as a single, unitary actor. One could then, alternatively, imagine a principal-agent framework with the administration being the government's agent for the implementation of development aid. In this case, a change in government ideology toward environmental preferences could lead to an additional incentive for the aid administration to over-report climate related projects. The principal-agent framework would thus lead to very different predictions for the relationship between government ideology and over-coding. As we cannot draw on any prior studies to clarify this theoretical argument, we will have to rely on the results of our econometric analysis to see whether our simplified model, or rather a more complex theoretical framework (including a principal-agent relationship between the government and the aid administration), is more appropriate to describe the empirical evidence.

\section{OPERATIONALIZATION AND ECONOMETRIC ESTIMATION STRATEGY}

We can test the three hypotheses using the project-level aid data provided by AidData (Tierney et al., 2011) in combination with political, economic, and environmental data from other sources. As we want to explain the donors' coding decision, the dependent variable is based on the Rio marker reported to the DAC. We generate a dummy variable "Rio dummy" that takes the value 1 if a donor reports that his/ her project is climate change-relevant (i.e., with mitigation as the principal objective or among the important objectives), and 0 otherwise. For some donors we cannot clearly distinguish between those projects which they assessed as climate change-irrelevant and those projects which they did not assess at all (in particular for the United States which did not use zero-codes at all). Therefore, all of these will be coded as 0 in our Rio dummy. ${ }^{7}$

As an alternative dependent variable, we will directly use our dummy for "over-coding" taking the value of 1 if we find clear evidence that the project has no link to either mitigation or adaptation activities while the Rio dummy is still reported as 1 . Unclear cases are coded as 0 rather than 1 , that is, they are considered as correct.

We use different variables to measure the environmental preferences of the population (as necessary to test Hypothesis 1). First, we explore the World Values Survey (WVS) which provides us with the percentage of the population in each donor country considering global warming or the greenhouse effect as a very serious problem (World Values Survey Association., 2009). Unfortunately, the information is only available for a single year (2005). Nevertheless, assuming that - at least relative to other countries - these preferences stay relatively stable over time, we can use these figures as a general estimate of cross-country differences in the population's valuation of global environmental problems, and even more specifically, the problem of climate change. For some countries, for which data on this question were not available, we used information from other questions related to the environment from the 2005 and earlier WVS surveys to impute the missing values. Only for one donor (Greece) no imputations were possible because it did not participate in any of these surveys.

Second, we assume that environmental preferences of the population should find their reflection in votes for green parties, so that we can use the share of green seats in national parliaments as a second indicator of the relevance of environmental objectives in the population. These data are available from Armingeon, Potolidis, Gerber, and Leimgruber (2008).

Third, we consider the rate of unemployment as an indicator of the relative salience of environmental problems. Our expectation is that in periods of high unemployment, people will be less concerned with environmental issues. As business cycles do not necessarily move in line with electoral cycles, this variable might capture some of the variation in preferences which is not covered by the more direct measure of preferences reflected in electoral outcomes. Data on unemployment are available from the World Bank's (2009a) World Development Indicators (WDI).

Let us now turn to the variables required to test our other hypotheses. The information of the population about climate policy issues (as required for Hypothesis 2) is measured by a count of press articles referring to climate change in their abstract or introductory paragraph. As we cannot assess the press in all national languages, we consider only one relatively widely read international newspaper, the "New York Times". While this does not allow us to explore cross-country variation in the level of information, it should capture variation over time at the global level. The data on this variable were obtained through keyword search in LexisNexis. (2010).

Regarding the preferences of the government (Hypothesis 3) we consider several variables. First, we assume that green or, more generally, left governments tend to have environmental preferences. As environmental preferences are only imprecisely reflected on a left-right dimension (Knill et al., 2010, p. 304), the ideal indicator would more closely reflect party positions (e.g., the indicator based on the assessment of party manifestos by Cusack and Engelhardt (2002)). However, these data are not available for most of the time period relevant for the Rio coding. We thus do not see any alternative to the measure of the traditional left-right dimension. In this context, we use the index of cabinet composition developed by Schmidt (1992) and updated by Armingeon et al. (2008). The index takes on values from 1 (hegemony of right-wing and center parties), to 5 (hegemony of social-democratic and other left parties).

Second, we suppose that the relative Kyoto gap, that is, the difference between the national emission target adopted in the framework of the Kyoto Protocol and current emission levels, divided by the base year emissions level, could provide further information on government preferences. If the government is itself responsible for the emission reduction target, a stringent target (and thus a high initial relative gap) is a direct reflection of the government's position on this topic. In other words, the stronger the government's environmental preferences, the more stringent should be the Kyoto target. For later governments who inherit the target, the remaining gap is proportionate to the necessity of action. If the target is eventually not met, the government will lose credibility at the international level. Thus even if the "green" beliefs are not fully authentic, the fears to lose face internationally may increase the preferences for concrete environmental policy action. Data on the Kyoto gap are available from IGES. (2009).

Third, we conjecture that extreme meteorological events with severe consequences in any particular donor country (such as flooding, storms, heat waves or droughts) will influence the government's perceptions about the general need for climate policies. Of course, such events also influence the preferences of the population as a whole. However, it is the effect on the government's own preferences which distinguishes this variable from other variables such as unemployment. It is through the effect on government preferences that we expect a reduction rather than an increase in over-coding. We extract data on extreme events from publications by the World 
Meteorological Organization (WMO, various years) and construct a corresponding dummy variable.

Finally, we will consider a certain number of controls. Most importantly, when we use the Rio dummy as our dependent variable, we need to control for actual mitigation and adaptation. This control (which is possible only on the basis of the transparency on project level aid provided by the new AidData data) is central for our analysis. Without this control, the potential relevance of political-economic variables might well refer to actual climate aid; but with this control, it only refers to variations in reporting, at given levels of actual climate aid. In our recoding procedure described in Section 2 and Appendix A, we generate two separate dummy variables indicating a project's relevance for either mitigation or adaptation. It is worthwhile to distinguish between both because of the Rio marker's official focus on mitigation only. Controlling for mitigation and adaptation separately, we will be able to make out to what extent this has been incorrectly interpreted to include adaptation.

In addition, we control for income and economic growth in donor countries. The underlying idea is that these factors may influence the government budget constraints when considering climate related interventions. While the general level of income (GDP per capita) affects the overall level of resources and therefore shapes government spending in the long-run, temporary relaxation of the budget constraint is determined by economic growth. We thus expect that with a higher level of income and in periods of high growth there is less need to use over-coding since finance for truly climate related measures is more easily available.

As yet another macroeconomic variable, we consider the share of agricultural value added in donor GDP. In developed countries, a strong agricultural sector usually goes hand in hand with important lobbying activities. As national policies against climate change often have a negative impact on immediate earning prospects in agriculture due to increase of energy costs, these lobbying activities tend to be directed against such interventions or against the mere perception of a need for action. In no industrialized country relevant mitigation policies have been introduced in the agricultural sector, whereas in a significant share of OECD countries the politically powerful heavy industry lobby was unable to prevent introduction of emissions trading systems or carbon taxes. In New Zealand, for instance, in 2003 the agricultural lobby immediately led politicians to shelve a proposal for a tax on livestock methane emissions (Fickling, 2003). Such lobby interventions may override the preferences of the government and/or the preferences of the population as a whole. These additional variables are available from the WDI database. (Missing values for all our macroeconomic variables are imputed using linear imputation based on related variables from the same dataset.)

Apart from macroeconomic variables, we consider a few additional controls which may be relevant to avoid omitted variable bias in our regressions. First, we consider that the age composition of the population in donor countries may interfere with voters' climate policy-related preferences and therefore be relevant in the context of the variables used to assess Hypothesis 1. The neglect of climate change today is equivalent to living on the future generations' resources. A younger population may have stronger preferences for environmental policies if it feels more directly concerned by its consequences than older people. If, however, the detrimental effect of today's neglect of climate change is expected to be relevant only further in the future, it might also be that older people care more. In their empirical assessment, Torgler, Valinas, and Macintyre (2008) find that older people tend to express less support for general environmental policies, but show even more active engagement for environmental objectives. Since the relationship between age and environmental preference is not clear, we cannot use this variable to test Hypothesis 1 . This is why we simply add this variable as a control. To capture the impact of age, we include the share of the population aged 65 and over which is available from the OECD (2008).

Another relevant control may be project size. On the one hand, any government wishing to impress its population by a high share of climate change-relevant aid will be able to do so more easily with financially large projects. After all, financial flows rather than project numbers are usually presented in published statistics. This implies that, for political reasons, large projects may tend to be over-coded more frequently. At the same time, the project description for big projects could simply be less detailed, so that even if climate policy is indeed among the important objectives, this may not always have been recognizable for our recoding. In this case, a positive relationship between project size and over-coding may simply be an artifact of imprecise reporting. Unfortunately, there is no way to distinguish between these two effects.

We also introduce a control variable which directly captures part of the reporting problem related to a lack of diligence or uninformed coding decisions, rather than politico-economic motives. This is possible if we assume that the quality of coding is positively related to a donor country's general level of bureaucratic quality. Bureaucratic quality can be measured with the indicator on government effectiveness provided by the World Bank's (2009b) World Governance Indicators (WGI). According to its definition, this indicator captures "perceptions on the quality of public services, the quality of the civil service and the degree of its independence from political pressures, the quality of policy formulation and implementation, and the credibility of the government's commitment to such policies" (Kaufmann, Kraay, \& Mastruzzi, 2009, p. 6). As this variable was only created on a bi-annual basis until 2003, we use linear interpolations from data of neighboring years to impute missing values.

Finally, we include one project level control variable indicating whether the recipient country is a member of the group of Small Island Developing States (SIDS) (UN., 2007). In these countries, most projects are climate relevant in some way or the other due to their high vulnerability to climate change. Therefore, by definition, there may be less scope for overcoding.

Details on all variable definitions and sources are provided in Appendix C. Unfortunately, many of the explanatory variables, notably the political variables most important for our analysis, are only available until the end of 2007. As mentioned earlier, the starting year of our analysis is 1995 , since no country used the Rio marker for any earlier year. This leads to an overall time period covered from 1995 to 2007 .

The estimation approach needs to reflect the structure of the data, notably the fact that any given donor carries out a multitude of projects which cannot be considered as fully independent from each other. This leads us to adopt a two-level hierarchical model in which projects are nested in donors. However, there is some risk that unobserved donor characteristics might induce bias. We thus test the typical two-level (random effects) model against a model with donor fixed effects, using a standard Hausman test. This test consistently rejects the random effects model. We therefore proceed with the fixed effects model here. It should be noted, however, that due to the large sample size the precision of estimated coefficients is very high and the difference between the coefficient estimates in both models is hardly visible. 
Apart from projects being nested in donors, there may be other interdependencies between our observations induced by the structure of our data. For instance, certain years could be of particular relevance leading to a general effect on all projects across all donors. One could imagine that the year 1998 when most donors introduced the Rio coding, should be a matter in case. Surprisingly, we do not find much evidence for such year specific effects. They are mostly insignificant, so that we eventually decided to leave them out of the final specification. Results of other variables remain unaffected.

In addition, there could be unknown relationships between projects in certain sectors or regions which we have not explicitly taken into account through any variables in the model. This suggests using estimation methods robust to serial correlation and heteroskedasticity.

As our dependent variable is binary (reflecting the coding decision) the problem becomes more complicated, however, since binary response models (logit or probit) are inconsistent in the presence of heteroscedasticity or unmeasured heterogeneity (Greene, 2002, p. 673f). In other words, if we believe that we need robust estimation, the whole model is incorrectly specified in the first place. We therefore proceed by presenting both, a logit estimation under the assumption of homoscedasticity and no autocorrelation, and a linear probability model to assess what happens if we relax this assumption and use a robust estimation for our variance-covariance matrix.

As an additional robustness check, we estimated the whole model at country level, using shares of over-coded projects as the dependent variable. This considerably reduces the number of observations and therefore, the precision of the estimation, and also induces us to drop or average certain project-level variables. However, it avoids the problem of unknown interdependencies of observations at the project level. Moreover, it is the only specification where the Hausman test suggests RE-estimation, so that time invariant variables can also be taken into account.

\section{POLITICO-ECONOMIC DETERMINANTS OF CODING MISMATCH: ECONOMETRIC EVIDENCE}

Let us now examine the results of our analysis. Table 2 presents six regressions. Regressions $\mathrm{A}-\mathrm{C}$ use the Rio dummy as the dependent variable and control for mitigation and adaptation, while Regression D and E directly use our dummy for over-coding. Regressions A, B and D are based on the (robust) linear probability model, whereas Regressions $\mathrm{C}$ and $\mathrm{E}$ are logit regressions. Regression A differs from Regression $\mathrm{B}$ in that we drop two of the macroeconomic variables (unemployment and GDP per capita) which are clearly insignificant. Finally, Regression $F$ presents the results of the country level estimation using the annual share of over-coded projects as the dependent variable.

Regressions $\mathrm{A}-\mathrm{C}$ which use the donor's coding decision as the dependent variable allow us to include our coding of mitigation and adaptation to control for the match of coding decisions with the projects' actual climate relevance. As our descriptive statistics have already suggested, instead of a one-to-one relationship between mitigation and a positive Rio marker, our mitigation dummy increases the probability of a positive Rio marker by only about $34-42 \%$. Projects related to adaptation increase this probability by another 6$10 \%$ (depending on the different specifications). Much of the overall variance in the dependent variable remains unexplained, and we will now see whether some of it is indeed systematically related to our politico-economic variables.
We obtain the clearest results for our two major political variables, the share of green parliamentarians and cabinet composition. The latter is significantly negative throughout, suggesting that the ideological position of government clearly plays a role for over-coding - with over-coding being less prevalent in left-wing governments (Hypothesis 3). This is in line with our conjecture that, due to their own preferences, these governments may tend to truly act on climate related issues rather than to simply rely on over-coding. ${ }^{9}$

In most regressions the substantive effect lies between -0.5 and -1 percentage points for a full switch from hegemony of right parties to hegemony of left parties. If the left-right dimension only imprecisely captures the governments' environmental preferences, the true effect should be even stronger.

Among the other variables included as more indirect measures of government preferences, the effect of meteorological extreme events is also relatively clear: If the donor country is hit by a meteorological extreme event, over-coding tends to be reduced by $0.1-0.5$ percentage points. This effect is sustained over the following year. In the country level regression (Regression F) this effect is insignificant, but similar in size.

For the Kyoto gap, coefficient estimates also have the expected sign but they are small (as they refer to a change of the gap by $100 \%$ ) and significant only in regressions without robust standard errors (Regressions $\mathrm{C}$ and $\mathrm{E}$ ).

When distinguishing donor governments' preferences from the preferences of their population to assess the specific effect of the latter (Hypothesis 1), our most direct variable is the share of green parliamentarians. As already mentioned, this variable appears to be clearly relevant. Our results suggest that increasing the share of green party representatives in a national parliament by 1 percentage point leads to a 0.1 percentage point increase of projects coded as climate relevant, irrespective of the projects' actual relationship to mitigation or adaptation. The positive coefficients are significant in all but two regressions, but even there, they fall only slightly under the threshold of a $10 \%$ significance level. These results are in line with our conjecture that, ceteris paribus, a population's ecological preferences, as expressed in the votes at national elections, lead to higher over-coding.

We do not find significant effects for the other two variables introduced to measure public preferences, that is, unemployment and the expressed concern about global warming. Generally, the effect of our macroeconomic variables (including those introduced as controls) is far less robust than the effect of many other variables. This seems to be partially related to their correlation among each other. We therefore drop the unemployment variable as well as GDP per capita from Regressions B-F.

Hypothesis 2 on the role of media information in reducing over-coding is less clearly in line with the empirical evidence. As expected the coefficients are negative, but it is significant only in 2 out of 6 regressions. Moreover, the substantive effect is rather small: One hundred more New York Times articles mentioning climate change in their abstract or introduction in any given year only reduce over-coding by only $0.05-0.5$ percentage points.

Moreover, considering the lag of our information variable, we find that the effect is reversed only one year later. Our interpretation is that information first increases the call for truly climate relevant interventions and the critical scrutiny of government action in this respect. However, after some time, if the information effort is not sustained, people reduce their effort of critical policy assessment so that simple statistical embellishment tends to become the governments' preferred strategy. All in all, the substantive effect is weak, which may be related 
Table 2. Estimation results ${ }^{\mathrm{a}}$

\begin{tabular}{|c|c|c|c|c|c|c|}
\hline $\begin{array}{l}\text { Regression number } \\
\text { Regression type } \\
\text { Dependent variable }\end{array}$ & $\begin{array}{l}\text { (A) } \\
\text { FE, linear } \\
\text { Rio dummy }\end{array}$ & $\begin{array}{l}\text { (B) } \\
\text { FE, linear } \\
\text { Rio dummy }\end{array}$ & $\begin{array}{c}\text { (C) } \\
\text { FE, logit } \\
\text { Rio dummy }\end{array}$ & $\begin{array}{l}\text { (D) } \\
\text { FE, linear } \\
\text { Over-coding }\end{array}$ & $\begin{array}{c}(\mathrm{E}) \\
\mathrm{FE}, \operatorname{logit}^{\mathrm{c}} \\
\text { Over-coding }\end{array}$ & $\begin{array}{c}(\mathrm{F}) \\
\text { RE,linear } \\
\text { Share of over-coding }\end{array}$ \\
\hline \multicolumn{7}{|c|}{ Environmental preferences, donor country population } \\
\hline Green parliamentarians, in $\%$ & $\begin{array}{l}0.001 \\
(0.13)\end{array}$ & $\begin{array}{l}0.001 \\
(0.13)\end{array}$ & $\begin{array}{l}\mathbf{0 . 0 0 1} \\
(0.00)\end{array}$ & $\begin{array}{l}\mathbf{0 . 0 0 1} \\
(0.02)\end{array}$ & $\begin{array}{c}\mathbf{0 . 0 0 0 2} \\
(0.00)\end{array}$ & $\begin{array}{l}\mathbf{0 . 0 0 1} \\
(0.09)\end{array}$ \\
\hline Unemployment, in $\%$ & $\begin{array}{c}-0.0003 \\
(0.76)\end{array}$ & & & & & \\
\hline Global warming very important & & & & & & $\begin{array}{l}0.002 \\
(0.93)\end{array}$ \\
\hline \multicolumn{7}{|l|}{ Information } \\
\hline New York Times & $\begin{array}{c}-4.63 \mathrm{e}-05 \\
(0.13)\end{array}$ & $\begin{array}{c}-4.56 \mathrm{e}-05 \\
(0.14)\end{array}$ & $\begin{array}{c}-\mathbf{2 . 5 8 e}-\mathbf{0 5} \\
(0.00)\end{array}$ & $\begin{array}{c}-1.36 \mathrm{e}-05 \\
(0.26)\end{array}$ & $\begin{array}{c}-7.89 e-06 \\
(0.00)\end{array}$ & $\begin{array}{c}4.07 e-06 \\
(0.72)\end{array}$ \\
\hline New York Times, lagged & $\begin{array}{r}0.0001 \\
(0.18)\end{array}$ & $\begin{array}{r}0.0001 \\
(0.24)\end{array}$ & $\begin{array}{c}\mathbf{0 . 0 0 0 1} \\
(0.00)\end{array}$ & $\begin{array}{c}-1.13 \mathrm{e}-05 \\
(0.77)\end{array}$ & $\begin{array}{c}\mathbf{1 . 6 6 e}-\mathbf{0 5} \\
(0.00)\end{array}$ & $\begin{array}{c}0.0006 \\
(0.12)\end{array}$ \\
\hline \multicolumn{7}{|l|}{ Donor government preferences } \\
\hline Cabinet composition, 1 right -5 left & $\begin{array}{c}-\mathbf{0 . 0 0 2} \\
(0.06)\end{array}$ & $\begin{array}{c}-\mathbf{0 . 0 0 2} \\
(0.02)\end{array}$ & $\begin{array}{c}-\mathbf{0 . 0 0 0 4} \\
(0.00)\end{array}$ & $\begin{array}{c}-\mathbf{0 . 0 0 1} \\
(0.06)\end{array}$ & $\begin{array}{c}-\mathbf{0 . 0 0 0 2} \\
(0.01)\end{array}$ & $\begin{array}{c}-\mathbf{0 . 0 0 1} \\
(0.03)\end{array}$ \\
\hline Kyoto gap relative to base year & $\begin{array}{l}-0.003 \\
(0.85)\end{array}$ & $\begin{array}{c}-0.001 \\
(0.96)\end{array}$ & $\begin{array}{c}-\mathbf{0 . 0 0 7} \\
(0.02)\end{array}$ & $\begin{array}{c}-0.010 \\
(0.31)\end{array}$ & $\begin{array}{c}-\mathbf{0 . 0 0 4} \\
(0.01)\end{array}$ & $\begin{array}{l}0.005 \\
(0.51)\end{array}$ \\
\hline Extreme events & $\begin{array}{c}-\mathbf{0 . 0 0 5} \\
(0.02)\end{array}$ & $\begin{array}{c}-\mathbf{0 . 0 0 5} \\
(0.00)\end{array}$ & $\begin{array}{c}-\mathbf{0 . 0 0 2} \\
(0.00)\end{array}$ & $\begin{array}{c}-\mathbf{0 . 0 0 2} \\
(0.02)\end{array}$ & $\begin{array}{c}-\mathbf{0 . 0 0 1} \\
(0.00)\end{array}$ & $\begin{array}{c}-0.002 \\
(0.47)\end{array}$ \\
\hline Extreme events, lagged & $\begin{array}{c}-\mathbf{0 . 0 0 5} \\
(0.05)\end{array}$ & $\begin{array}{c}-\mathbf{0 . 0 0 5} \\
(0.03)\end{array}$ & $\begin{array}{c}-\mathbf{0 . 0 0 3} \\
(0.00)\end{array}$ & $\begin{array}{c}-\mathbf{0 . 0 0 3} \\
(0.01)\end{array}$ & $\begin{array}{c}-\mathbf{0 . 0 0 2} \\
(0.00)\end{array}$ & $\begin{array}{c}-0.001 \\
(0.63)\end{array}$ \\
\hline \multicolumn{7}{|l|}{ Controls: actual climate relevance } \\
\hline Mitigation & $\begin{array}{l}\mathbf{0 . 4 1 6} \\
(0.00)\end{array}$ & $\begin{array}{l}\mathbf{0 . 4 1 6} \\
(0.00)\end{array}$ & $\begin{array}{l}\mathbf{0 . 3 3 7} \\
(0.00)\end{array}$ & & & \\
\hline Adaptation & $\begin{array}{l}\mathbf{0 . 0 9 5} \\
(0.02)\end{array}$ & $\begin{array}{l}\mathbf{0 . 0 9 5} \\
(0.02)\end{array}$ & $\begin{array}{l}\mathbf{0 . 0 6 4} \\
(0.00)\end{array}$ & & & \\
\hline \multicolumn{7}{|l|}{ Other controls } \\
\hline GDP growth, in $\%$ & $\begin{array}{c}-0.0005 \\
(0.58)\end{array}$ & $\begin{array}{c}-0.0006 \\
(0.50)\end{array}$ & $\begin{array}{c}-\mathbf{0 . 0 0 0 3} \\
(0.00)\end{array}$ & $\begin{array}{c}-0.0003 \\
(0.61)\end{array}$ & $\begin{array}{c}-\mathbf{0 . 0 0 0 2} \\
(0.00)\end{array}$ & $\begin{array}{c}-0.0002 \\
(0.68)\end{array}$ \\
\hline GDP per capita & $\begin{array}{c}-1.39 \mathrm{e}-07 \\
(0.85)\end{array}$ & & & & & \\
\hline Agricultural value added, in $\%$ & $\begin{array}{c}-0.002 \\
(0.77)\end{array}$ & $\begin{array}{c}-0.002 \\
(0.74)\end{array}$ & $\begin{array}{c}-\mathbf{0 . 0 0 1} \\
(0.04)\end{array}$ & $\begin{array}{c}-\mathbf{0 . 0 0 5} \\
(0.09)\end{array}$ & $\begin{array}{c}-\mathbf{0 . 0 0 2} \\
(0.00)\end{array}$ & $\begin{array}{c}-0.001 \\
(0.11)\end{array}$ \\
\hline Population 65 and over, in $\%$ & $\begin{array}{l}\mathbf{0 . 0 0 8} \\
(0.00)\end{array}$ & $\begin{array}{l}\mathbf{0 . 0 0 8} \\
(0.00)\end{array}$ & $\begin{array}{l}\mathbf{0 . 0 0 3} \\
(0.00)\end{array}$ & $\begin{array}{l}\mathbf{0 . 0 0 1} \\
(0.13)\end{array}$ & $\begin{array}{l}\mathbf{0 . 0 0 1} \\
(0.00)\end{array}$ & $\begin{array}{c}-0.0002 \\
(0.71)\end{array}$ \\
\hline Big project & $\begin{array}{l}0.005 \\
(0.21)\end{array}$ & $\begin{array}{l}0.005 \\
(0.20)\end{array}$ & $\begin{array}{l}\mathbf{0 . 0 0 2} \\
(0.00)\end{array}$ & $\begin{array}{c}0.03 \\
(0.13)\end{array}$ & $\begin{array}{l}\mathbf{0 . 0 0 1} \\
(0.00)\end{array}$ & \\
\hline Government effectiveness & $\begin{array}{c}-\mathbf{0 . 0 2 5} \\
(0.01)\end{array}$ & $\begin{array}{c}-\mathbf{0 . 0 2 5} \\
(0.01)\end{array}$ & $\begin{array}{c}-\mathbf{0 . 0 1 1} \\
(0.00)\end{array}$ & $\begin{array}{c}-0.009 \\
(0.02)\end{array}$ & $\begin{array}{c}-\mathbf{0 . 0 0 4} \\
(0.00)\end{array}$ & $\begin{array}{c}-0.002 \\
(0.60)\end{array}$ \\
\hline SIDS & $\begin{array}{c}-0.0003 \\
(0.77)\end{array}$ & $\begin{array}{c}-0.0003 \\
(0.78)\end{array}$ & $\begin{array}{c}-0.0002 \\
(0.46)\end{array}$ & $\begin{array}{c}-0.007 \\
(0.21)\end{array}$ & $\begin{array}{c}-\mathbf{0 . 0 0 0 4} \\
(0.09)\end{array}$ & \\
\hline Prob $>$ (Wald) $\mathrm{Chi}^{2}$ or Prob $>F$ & 0.00 & 0.00 & 0.00 & 0.00 & 0.00 & 0.00 \\
\hline Observations & 557,278 & 557,278 & 557,278 & 557,278 & 557,278 & 259 \\
\hline Number of donors & 21 & 21 & 21 & 21 & 21 & 20 \\
\hline Number of years & 13 & 13 & 13 & 13 & 13 & 13 \\
\hline
\end{tabular}

${ }^{a} P$-values in parentheses, constants and fixed effects not presented. Coefficients significant at the $10 \%$ level or above are presented in bold.

${ }^{\mathrm{b}}$ Robust estimation with standard errors clustered by donor.

${ }^{\mathrm{c}}$ Marginal effects, evaluated at the mean of the explanatory variables; for dummies, discrete change from 0 to 1 .

dEstimation at donor, rather than at project level. At this level, the Hausman test suggests RE estimation. One country observation is lost due to missing values for the "global warming" variable.

to the fact that media information on climate-change related issues is generally rather superficial.

As far as our control variables are concerned, the most significant results are obtained for the share of elderly people (which tends to increase over-coding), the general quality of bureaucratic services (which tends to decrease over-coding), and the share of agricultural value added in donor countries (which equally tends to decrease over-coding). While fully significant in only two regressions, there is also some evidence for the expected stronger coding gap for large projects.
The overall picture clearly shows that politico-economic variables systematically influence donors' coding of aid projects. While the effects observed are relatively small in magnitude, for the most part, they are clearly different from zero and relatively robust across different specifications - at least in terms of direction and significance. Especially the impact of government ideology and of public environmental preferences is clearly supported by the data. Media information appears to have a smaller effect than expected, which may be related to the relatively superficial coverage of climate policy issues. 
At the same time, the strong evidence for adaptation related coding indicates a wide-spread misunderstanding of the current Rio marker. Our control for government effectiveness also suggests that there may be problems of coding diligence at least in some countries.

All in all, our different political-economic models allow us to explain up to about $15 \%$ of the variance in the respective dependent variables.

\section{CONCLUSIONS}

Discrepancies between climate coding of aid projects reported to the DAC and a keyword based examination of actual climate change-relevance have led us to conjecture that climate coding may be motivated by political factors, at least to some extent. As we cannot draw from prior theoretical analysis on politically motivated coding decisions, we derive our hypotheses based on a conceptual framework related to the general literature on public choice, the political economy of aid, and the political economy of environmental policy. The analysis remains largely exploratory and many interpretations may lend themselves to further debate.

Nevertheless, the empirical results are generally consistent with our hypotheses. They are tested using project-level aid data and country-level political data for 21 DAC donors from 1995 to 2007. Keyword search in the project descriptions of the AidData database and complementary hand-coding allows us to assess all projects for their actual climate change-related content, and to thereby construct the most relevant control variable.
The econometric model takes into account the hierarchical structure of the data, whereby projects are nested in donor countries. We find that mitigation, the official focus of the DAC reported climate coding, only adds about one third to the probability to actually receive the so-called climate related "Rio marker" by DAC donors. Relevance to adaptation, which is excluded by the formal definition of the Rio marker, roughly adds up to another $10 \%$. The latter may, at least in part, be due to a misunderstanding of the Rio marker.

In addition to these two variables characterizing the substance of the project, a number of political variables are systematically related to the coding decision. In line with the politico-economic framework, we find that general ecological preferences of the donor country population and the ideological preferences of the donor government influence the coding decision. While the former leads to stronger over-coding, the latter leads to reduced over-coding - presumably because in this case, the government pushed for actual climate policy. We also find some evidence for the impact of information on climate policy by the media, although this effect is only relatively small and changes from a positive effect of information, to a negative one (implying more over-coding) in the following year.

All in all, our results imply that for a given relevance of any project to climate change mitigation or adaptation, politicoeconomic factors significantly influence the statistics reported to the DAC. What we observe in the data is clearly inconsistent with a simple random error around an otherwise correct coding of climate relevant aid.

\section{NOTES}

1. Lead reduction is needed to employ catalytic converters. It thus generates twofold environmental benefits by reducing both lead and $\mathrm{NO}_{x}$. But these benefits do not arise with respect to greenhouse gases. In fact, $\mathrm{CO}_{2}$ emissions actually increase since the efficiency of motors is reduced.

2. For more recent analyses, see for example Fleck and Kilby (2010) and Berthélemy (2006); for a meta-analysis of some of this literature, see Doucougliagos and Paldam (2008).

3. We use the term "climate aid" as a short hand for climate changerelated aid.

4. The aid activities listed in the AidData database also include nonproject aid, for example, budget support, other program funding, or small activities such as feasibility studies (Tierney et al., 2011). These distinctions do not matter in the context of our analysis. As the vast majority of activities are traditional aid projects, we interchangeably use the term "projects" for ease of exposition.

5. "Activities receive a significant score (score "1") where climate change adaptation was an important, but not principal objective. The score not targeted (score " 0 ") means that the activity has been found not to be targeting significantly climate change adaptation." (OECD-DAC 2009b, p. 1 , emphasis added by the authors).

6. While it might be safer to include these categories if one wants to make sure to cover all possibly climate related projects, we exclude them because the probability that they are truly related to climate change mitigation (without further mentioning of this relationship) appears to be relatively small.
7. Note that this coding decision has both technical and theoretical reasons. If noncoded projects were simply omitted, for some countries, we would not have any variance on the dependent variable any more. Thus countries like the US would have to be dropped from our analysis. From a theoretical perspective, we suggest that, when the issue is to demonstrate climate-friendly activities through aid allocation, the political decision not to assess the projects is substantially equivalent to coding them as climate change-irrelevant. Appendix provides information on the share of projects noncoded by individual donor country.

8. We initially considered to also include a number of well-known European newspapers such as "Le Monde", "The Guardian", "Die Welt", and "El Pais", but the time series are not long enough. Moreover, it turns out that information provided on climate change is strongly correlated across these different newspapers (for the number of articles per year, we obtain a correlation coefficient of $88 \%$ between the "New York Times" and "Le Monde", and of over 95\% for the "New York Times" and any of the three other newspapers.

9. Note that the first part of this conjecture cannot be tested with climate aid data. Government preferences for environmental protection tend to be positively correlated to government preferences for development aid. An environmentally oriented government should thus not be expected to substitute action against climate change for traditional development projects, but rather, to carry out additional mitigation activities (e.g., through emission reduction at home). Indeed, actual climate aid (as opposed to climate aid related coding) seems to be relatively unaffected by any of the political variables above (Michaelowa and Michaelowa, 2011). 


\section{REFERENCES}

AidData (2010). PLAID 1.9: Final development release of the PLAID database. $<$ http://www.AidData.org $>$ Accessed 15.02.2010.

Armingeon, K., Potolidis, P., Gerber, M., \& Leimgruber, P. (2008). Comparative political data. Set (CPDS I), 1960-2007. University of Berne. $\quad<$ http://www.nsd.uib.no/macrodataguide/set.html?id=6\&sub $=2>$ Accessed 15.03.2010.

Bättig, M., \& Bernauer, T. (2009). National institutions and global public goods: Are democracies more cooperative in climate change policy? International Organization, 63(02), 281-308.

Berthélemy, J. (2006). Bilateral donors' interest vs. recipients' development motives in aid allocation: Do all donors behave the same? Review of Development Economics, 10(2), 179-194.

Blanke, A. (2002). Ecological tax reform in Germany and interest groups. International Review for Environmental Strategies, 3(1), 81-95.

Cusack, T., \& Engelhardt, L. (2002). The PGL file collection: File structures and procedures. Wissenschaftszentrum Berlin (WZB). $<\mathrm{http}: / /$ www.wzberlin.de/mp/ism/people/misc/cusack/d_sets.en.htm\#data> Accessed 2.05.2010.

Doucougliagos, H., \& Paldam, M. (2008). Aid effectiveness on growth: A meta study. European Journal of Political Economy, 24(1), 1-24.

Dreher, A., Sturm, J., \& Vreeland, J. (2009a). Global horse trading: IMF loans for votes in the United Nations security council. European Economic Review, 53(7), 742-757.

Dreher, A., Sturm, J., \& Vreeland, J. (2009b). Development aid and international politics: Does membership on the UN security council influence world bank decisions. Journal of Development Economics, $88(1), 1-18$.

Felder, S., \& Schleiniger, R. (2002). Environmental tax reform: Efficiency and political feasibility. Ecological Economics, 42(1-2), 107-116.

Fickling, D. (2003). Farmers raise stink over New Zealand 'Fart Tax'. The Guardian, [September 3].

Fleck, R., \& Kilby, C. (2010). Changing aid regimes? US foreign aid from the cold war to the war on terror. Journal of Development Economics, 91(2), 185-197.

Flues, F., Michaelowa, A., \& Michaelowa, K. (2010). What determines UN approval of greenhouse gas emission reduction projects in developing countries?. Public Choice, 145, 1-24.

Frankford, P. (2002). Zahlenschwindel. Die Zeit, No. 18.

Greene, W. (2002). Econometric analysis (5th ed.). Prentice-Hall: Upper Saddle River.

Hicks, R., Parks, B., Roberts, T., \& Tierney, M. (2008). Understanding the environmental impact of development assistance. Oxford, UK: Oxford University Press.

IGES. (2009). GHG Emissions Data, Kanagawa: Institute for Global Environmental Strategies. $<\mathrm{http}: / /$ www.iges.or.jp/en/cdm/report_kyoto.html\#ghg > Accessed 10.03.2010.

Kaufmann, D., Kraay, A., \& Mastruzzi, M. (2009). Governance matters VIII: aggregate and individual governance indicators, 1996-2008. World Bank policy research working paper no. 4978. Washington, DC: The World Bank.

Kilby, C. (2009). The political economy of conditionality: An empirical analysis of World Bank loan disbursements. Journal of Development Economics, 89(1), 51-61.

Knill, C., Debus, M., \& Heichel, S. (2010). Do parties matter in internationalised policy areas? The impact of political parties on environmental policy outputs in 18 OECD countries. European Journal of Political Research, 49(3), 301-336.

Lahiri, S., \& Michaelowa, K. (2006). The political economy of aid. Review of Development Economics, 10(2), [Special ed.]

LexisNexis. (2010). International news, $<\mathrm{http}$ ://www.lexisnexis.de/e-solutions/KSH/index.html $>$ Accessed 15.02.2010

List, J., \& Sturm, D. (2006). How elections matter: Theory and evidence from environmental policy. Quarterly Journal of Economics, 121(4), 1249-1281.

Maizels, A., \& Nissanke, M. (1984). Motivations for aid to developing countries. World Development, 12(9), 879-900.

Martens, B. (2002). The role of evaluation in foreign aid programmes. In Bertin Martens, Uwe Mummert, Peter Murrell, \& Paul Seabright (Eds.), The institutional economics of foreign aid (pp. 154-177). Cambridge, UK: University Press.
McKinley, R. (1978). The german aid relationship: A test of the recipient need and the donor interest models of the distribution of german bilateral aid 1961-70. European Journal of Political Research, 6(3), 235-257.

McKinley, R., \& Little, R. (1979). The US aid relationship: a test of the recipient need and the donor interest models. Political Studies, 27(2), 236-250.

Michaelowa, A., \& Michaelowa, K. (2007). Climate or development: Is ODA diverted from its original purpose? Climatic Change, 84(1), 5-22.

Michaelowa, A., \& Michaelowa, K. (2011). Old wine in new bottles? The shift of development aid towards renewable energy and energy efficiency. International Development Policy, Series, 2, 60-86.

Michaelowa, K., \& Bormann, A. (2006). Evaluation bias and incentive structures in bi- and multilateral aid agencies. Review of Development Economics, 10(2), 313-329.

Milner, H., \& Tingley, D. (2010). The choice for multilateralism: Foreign Aid and American Foreign Policy. <http://www.princeton.edu/ dtingley/MilnerTingley Multilateralism.pdf $>$ Accessed 30.04 .2010 .

OECD (2008). Employment and labour market statistics, population and labour force statistics (vol. 2008, release 01). Paris: OECD.

OECD-DAC. (1998). Definition of the rio marker on climate change (mitigation). http://www.oecd.org/dataoecd/18/31/44188001.pdf Accessed 7.03.2010.

OECD-DAC (2002a). Aid targeting the objectives of the Rio conventions 1998-2000, a contribution by the DAC secretariat for the information of participants at the world summit for sustainable development in Johannesburg. Paris: OECD.

OECD-DAC (2002b). Reporting directives for the creditor reporting system - addendum rio markers, DCD/DAC(2002)21/ADD. Paris: OECD.

OECD-DAC (2009a). OECD development assistance committee tracks aid in support of climate change mitigation and adaptation, information note. Paris: OECD.

OECD-DAC. (2009b). Measuring aid targeting the objective of the United Nations framework convention on climate change. November, $<\mathrm{http}$ //www.oecd.org/dac/stats/rioconventions > Accessed 15.02. 2010.

OECD-DAC (2010). Reporting directives for the creditor reporting system - addendum on the climate change adaptation marker, DCD/ $D A C(2007) 39 / F I N A L / A D D 3$. Paris: OECD.

Roberts, T., Weissberger, M., \& Peratsakes, C. (2010). Trends in official climate finance: Evidence from human and machine coding. Mimeo: Brown University/College of William and Mary.

Roberts, T., Starr, K., Jones, T., \& Abdel-Fattah, D. (2008). The reality of official climate aid. Oxford, UK: Oxford Energy and Environment Comment.

Schmidt, Manfred G. (1992). Regierungen: Parteipolitische Zusammensetzung. In Manfred G. Schmidt (Ed.). Lexikon der Politik (Vol. 3, pp. 393-400). Munich: Die westlichen Länder, C.H. Beck.

Tierney, M. J., Nielson, D., Hawkins, D. G., Roberts, J. T., Findley, M. G., Powers, R. M., et al. (2011). More dollars than sense? Addressing knowledge scarcity in development finance [Special issue]. World Development Journal, 39, 1891-1906.

Torgler, B., Valinas, M. A. G., \& Macintyre, A. (2008). Differences in preferences towards the environment: The impact of a gender, age and parental effect. school of economics and finance discussion papers and working paper 227. Brisbane: Queensland University of Technology.

UN. (2007). Small Island developing states network. United Nations department of economic and social affairs. $<$ http://www.sidsnet.org/ 2.html > Accessed 10.03.2010.

Weaver, C. (2008). Hypocrisy trap: the World Bank and the poverty of reform. Princeton, NJ: Princeton University Press.

WMO (various years). WMO statement on the status of the global climate. World Meteorological Organization: Geneva.

Bank, World. (2009a). World development indicators 2009, CD Rom. Washington: The World Bank. 
World Bank. (2009b). Governance Matters, Worldwide Governance Indicators, 1996-2008, <http://info.worldbank.org/governance/wgi/ index.asp $>$ Accessed 10.02.2010.

World Values Survey Association. (2009). World Values Survey 1981-2008 Official Aggregate v.20090901. <http://www.worldvaluessurvey.org> Accessed 10.03.2010.
SUPPLEMENTARY DATA

The four Appendices A-D associated with this article can be found, in the online version, at doi:10.1016/j.worlddev.2011.07.020. 